\title{
Erratum to: Race, SES, and mathematics achievement conflicts: how policy and political climate affect academic achievement
}

\author{
Zayoni N. Torres $\cdot$ Ramon A. Moran
}

Published online: 17 October 2014

(C) FIZ Karlsruhe 2014

\section{Erratum to: ZDM Mathematics Education}

\section{DOI 10.1007/s11858-014-0609-8}

The original version of this article unfortunately contained a mistake. At the end of the first paragraph of Sect. 4, it should read:

These criteria included: qualitative empirical design studies with evident theoretical framing, methods, data sources, and interpretations; focus on HB 2281 in relation to any specific aspect of the MAS program; and found in a reputable source. This resulted in eight interpretive studies.

The online version of the original article can be found under doi:10.1007/s11858-014-0609-8.

Z. N. Torres $(\bowtie)$

University of Illinois at Chicago, 1040 West Harrison Street M/C

147, Chicago, IL 60607, USA

e-mail: ztorre4@uic.edu

R. A. Moran

University of Illinois at Chicago, 1761 West 97th Street,

Chicago, IL 60643, USA

e-mail: rmoran7@uic.edu 